\title{
Relações de confiança envolvendo consumidores de alimentos orgânicos: um estudo de caso em Sorocaba/SP
}

\section{Trust relationships involving organic food consumers: a case study in Sorocaba (in the state of São Paulo)}

Rodrigo Brezolin Buquera1 (D), Paulo Eduardo Moruzzi Marques ${ }^{1}$

1Programa de Pós-graduação Interunidade em Ecologia Aplicada, Escola Superior de Agricultura "Luiz de Queiroz", Universidade de São Paulo (USP), Piracicaba (SP), Brasil. E-mail: rodrigobbuquera@gmail.com, pmarques@usp.br

Como citar: Buquera, R. B., \& Marques, P. E. M. (2022). Relações de confiança envolvendo consumidores de alimentos orgânicos: um estudo de caso em Sorocaba/SP. Revista de Economia e Sociologia Rural, 60(spe), e251225. https://doi. org/10.1590/1806-9479.2021.251225

\begin{abstract}
Resumo: A partir da crítica ao modelo agroalimentar industrial produtivista, as redes alimentares alternativas emergem por meio, particularmente, de uma reaproximação entre produtor e consumidor, visando ao resgate de relações de confiança interpessoal. Nessas redes, destaca-se o interesse pelos alimentos orgânicos. Com esse ponto de partida, este artigo visa apresentar uma análise sobre as formas de confiança adotadas pelos consumidores de alimentos orgânicos, utilizando um estudo de caso sobre o município de Sorocaba/SP. Para tal propósito, foram realizadas entrevistas semiestruturadas, acrescidas de informações obtidas por um levantamento on-line prévio. Como resultados, foi observada uma clara distinção nas formas de confiança adotadas pelos consumidores, representadas pela valorização de mecanismos institucionais de reconhecimento orgânico e de relações interpessoais de confiança. Por outro lado, a falta de clareza do que são os alimentos orgânicos e seus mecanismos de reconhecimento abrem espaço para prosperar um mercado informal de orgânicos, no qual pairam dúvidas sobre a qualidade orgânica dos alimentos, em ambiente favorável a dissimulações e fraudes.
\end{abstract}

Palavras-chave: redes alimentares alternativas, consumo de alimentos orgânicos, reconhecimento orgânico, confiança, feiras orgânicas.

\begin{abstract}
From the criticism of the modern productivist agri-food system, the alternative food networks emerge through a rapprochement between producers and consumers, which aims the rescue the interpersonal trust relationships. In these networks, the interest in organic food is highlighted. With this starting point, this paper presents an analysis of the trust forms adopted by the organic food consumers, using as a study case the municipality of Sorocaba (in the state of São Paulo). For this purpose, semistructured interviews were performed, enhanced by data obtained via a previous online survey. As a result, there was a clear distinction between the consumers' trust forms, represented by the valorization of institutional mechanisms for organic recognition and the interpersonal trust relationships. On the other hand, the lack of clarity about what is organic food and its recognition mechanisms make room for an informal organic market to thrive, in which there are doubts about the organic quality, in an environment favorable to concealment and fraud.
\end{abstract}

Keywords: alternative food networks, organic food consumption, organic recognition, trust, organic street fairs.

\section{Introdução}

A produção e a distribuição de alimentos são compostas por uma cadeia de atividades construída historicamente, a qual pode ser chamada de "sistema agroalimentar", "regime alimentar" ou, para o caso daquele modernizado contemporâneo, "complexo agroindustrial". O sistema agroalimentar moderno pode ser entendido como o conjunto das operações que envolvem produção, transformação, distribuição, comercialização, assistência técnica e serviços 
financeiros (Paula, 2017). Tendo a industrialização como principal traço, suas lógicas são impostas pelo domínio de grandes corporações e do mercado financeiro (McMichael, 2016). A propósito, Van der Ploeg (2008) considera que esse modelo se dissemina com lógicas de um "império alimentar", absorvendo a agricultura, o consumo de alimentos e os esquemas reguladores agroalimentares. Suas características estruturais se fundam na permanente expansão de múltiplas fronteiras, geográficas e conceituais, e em poder assegurado pelo Estado que, enquanto mediador social, exerce um papel de guardião de normas, imprescindíveis às práticas imperiais de amplo alcance, ancoradas em padrões de homogeneidade que determinam inclusão no mercado agroalimentar e exclusão dele. Esse modelo agroalimentar industrial produtivista é alvo de diversas críticas em razão de seus impactos ambientais e altos níveis de exclusão social.

Como resultado dessa crítica, novas formas de interação no mercado têm emergido, que podem ser denominadas redes alimentares alternativas (RAA). Trata-se de construções coletivas que promovem mudanças nas atitudes e práticas relacionadas à produção e ao consumo de alimentos (Rossi \& Brunori, 2017). As RAA podem ser definidas como sistemas de abastecimento diferentes ou até mesmo em oposição às cadeias agroalimentares convencionais (Schneider \& Gazolla, 2017).

Quatro elementos principais marcam suas lógicas: (1) redução da distância entre produtor e consumidor, em contraposição às cadeias longas; (2) favorecimento de escala e tamanho reduzidos e uso de métodos alternativos (principalmente biológicos, orgânicos, artesanais, biodinâmicos e naturais); (3) preferência por locais de compra direta com o produtor, como feiras e grupos de consumo; e (4) estabelecimentos de compromissos sociais, econômicos e ambientais em torno da produção (Schneider \& Gazolla, 2017).

Nessas RAA, os consumidores privilegiam uma noção de qualidade normalmente não oferecida pelo sistema convencional. Nesta perspectiva, a demanda passa a orientar a produção, conferindo poder político aos consumidores. Nas RAA, o acesso à informação reconecta produtores e consumidores, diferentemente das cadeias convencionais, nas quais a transparência é limitada (Schneider \& Gazolla, 2017). Nesse processo de reconexão entre produtores e consumidores, a confiança se torna um dos fundamentos centrais (Cassol \& Schneider, 2017).

Entre os alimentos comercializados nas RAA, aqueles orgânicos constituem um segmento em franco crescimento, aumentando em média entre 15 e $20 \%$ anualmente em todo o mundo, enquanto a indústria alimentar como um todo expande entre 4 e $5 \%$ (Nierdele \& Marques, 2016). Por sua própria natureza, esses alimentos podem ser classificados como "bens de crença", pois representam valores considerados nos processos produtivos não evidentes no produto final. Com efeito, a qualidade orgânica requer práticas específicas de difícil observação pelo consumidor, demandando, assim, um sistema de confiança que valide atributos da produção orgânica (Daugbjerg et al., 2014; Holland, 2016; Portilho \& Castañeda, 2011).

Para o desenvolvimento deste artigo, é pertinente definir minimamente "confiança". A tarefa não é fácil, visto que o termo se encontra em um campo de disputa filosófica, possuindo diferentes interpretações e sentidos (Kjærnes et al., 2007; McKnight \& Chervany, 1996). Em linhas gerais, duas abordagens sociológicas principais mobilizam o conceito de confiança. A primeira diz respeito a uma confiança pessoal, que se vincula às relações interpessoais e às expectativas de um indivíduo para com o outro, abrangendo situações de interações diretas "face a face", muitas vezes denominada como confiança enraizada ou apenas "trust". Já a segunda se refere a uma confiança no sistema, ou seja, trata-se de uma forma impessoal direcionada às normas da organização social, com suas instituições e seus mecanismos de controle, tais como o governo, os mercados e os selos, também denominada confiança desenraizada ou "confidence" (Portilho \& Castañeda, 2011; Thorsøe, 2015; Truninger, 2013). 
Em ambos os casos, a confiança se relaciona com a capacidade de percepção e previsão de riscos (Kjærnes et al., 2007; Thorsøe, 2015). Com efeito, os processos cognitivos e psicológicos de compreensão e avaliação de ameaças - em que a confiança na informação e na qualidade da comunicação é crucial - tornam-se mais intensos na "sociedade de riscos", como proposto por Ulrich Beck (2011). De fato, o desenvolvimento de novas tecnologias, a globalização e as mudanças aceleradas nas relações sociais aumentam a percepção de perigos ambientais e sanitários, que, associados ao aumento do estímulo à reflexibilidade dos indivíduos, geram incertezas e um sentimento de descrença (Kjærnes et al., 2007).

Ao aprofundar a discussão sobre a confiança relacionada ao debate agroalimentar, Kjærnes et al. (2007) consideram três principais grupos de atores que interagem entre si: os agentes do mercado, que produzem e ofertam alimentos; o governo e as agências reguladoras; e os consumidores e seus representantes. Para este artigo, as relações de confiança abordadas estão centralizadas nos consumidores, discutindo como eles percebem e interagem com os agentes do mercado e as instituições governamentais reguladoras.

As relações de confiança nas RAA abrangem aspectos socioculturais e institucionais. Quanto à primeira dimensão, a confiança está ligada a expectativas compartilhadas socialmente. Os estudos das relações sociais aqui devem considerar os hábitos alimentares, o alimento ofertado, o lugar de compra e a forma de preparo dos alimentos. Em âmbito institucional, a confiança está ligada à performance dos mecanismos de regulação, tanto em sua eficácia quanto em sua legitimidade (Cassol \& Schneider, 2017). À medida que as cadeias produtivas se alongam, as relações de confiança interpessoais são substituídas por formas jurídicas de controle, como selos e certificações (Renting et al., 2017).

No Brasil, a agricultura orgânica é regulamentada pela Lei n 10.831, de 2003, que demarca as diferenças entre os produtos orgânicos e os não orgânicos. A lei dispõe sobre as formas para se obter o reconhecimento orgânico, com duas modalidades. A primeira se funda em certificação por um organismo de auditoria reconhecido oficialmente, como empresas certificadoras (seguindo critérios preestabelecidos), ou pelo sistema participativo de garantia (SPG). A segunda maneira é específica para a comercialização direta com os consumidores, restringindo-se a agricultores familiares inseridos em processos próprios de Organização de Controle Social (OCS), devidamente formalizados. No caso do reconhecimento orgânico por certificação, o produtor é autorizado a comercializar produtos orgânicos no território nacional utilizando selo específico, enquanto, nos casos de garantia de conformidade orgânica via OCS, os produtores recebem autorização para a comercialização direta local com o consumidor e também para o fornecimento a mercados institucionais. No caso das OCS, os produtos não podem contar com o uso de selo orgânico (Brasil, 2003).

No que se refere ao debate sobre confiança, a legislação brasileira de reconhecimento da agricultura orgânica incorpora tanto suas formas interpessoais (OCS) quanto os mecanismos institucionais de regulação (sistema de peritos), sob a forma dos selos e certificações. Estes últimos, para muitos especialistas, são um meio importante de garantir a qualidade orgânica (Daugbjerg et al., 2014; Thorsøe et al., 2016), mesmo havendo casos de descrença na certificação orgânica (Portilho \& Castañeda, 2011; Vega-Zamora et al., 2019). Outros autores consideram os mecanismos institucionais como um empecilho para a produção de orgânicos, visto que seu emprego exige muitos recursos (Nierdele \& Marques, 2016; Portilho \& Castañeda, 2011). Como resposta a esse problema, o Brasil inovou ao regulamentar a certificação participativa (SPG), uma reivindicação antiga dos movimentos sociais, constituindo-se em alternativa às custosas certificações por auditoria de empresas, além dos mecanismos de controle social (OCS) para venda direta ao consumidor em circuito curto (Nierdele \& Marques, 2016). 
Mesmo com essas diferentes modalidades de reconhecimento da produção orgânica, o debate acerca da legitimidade desses mecanismos é intenso. Para muitos movimentos sociais, esses processos de padronização e institucionalização da agricultura orgânica correspondem à sua submissão a uma lógica industrial que não atende às demandas dos pequenos produtos (Portilho \& Castañeda, 2011). O debate chega a um ponto em que é possível observar casos de agricultores que, mesmo produzindo sob as regras da agricultura orgânica, não aderem ao uso de selos e certificações: uma clandestinidade voluntária (Anjos \& Caldas, 2017).

Essa dualidade de formatos de confiança (interpessoais e mecanismos institucionais) implica diferentes maneiras com as quais os consumidores se relacionam com os produtos. Assim, a confiança pode se alicerçar em mecanismos institucionais de controle, particularmente selos e certificações, utilizando critérios técnicos. No entanto, nas RAA, em que há uma maior proximidade entre os produtores e consumidores, a confiança usualmente extrapola o caráter apenas técnico. Os consumidores não se valem apenas de informações sobre os produtos, mas também consideram valores e relações sociais para justificar suas práticas de consumo (Cassol \& Schneider, 2017).

Essa primazia na confiança pelas relações interpessoais permite que os selos sejam raramente utilizados (Nierdele \& Marques, 2016). Trata-se de uma característica muito diferente dos dispositivos institucionais de reconhecimento de qualidade orgânica, em que os selos e as certificações assumem um papel central para o estabelecimento de confiança.

Deste modo, também há aqueles que utilizam critérios tácitos, como relações de amizade, valores compartilhados e até mesmo preocupações políticas (Cassol \& Schneider, 2017). De fato, as expectativas dos consumidores em relação à estética (Truninger, 2013), gosto, saudabilidade e até impactos ambientais (Thorsøe et al., 2016) podem afetar a confiança nos alimentos orgânicos.

De toda maneira, a confiança nos alimentos orgânicos é fundamentalmente dependente do acesso à informação. Com efeito, muitos trabalhos indicam a associação entre confiança e informação como forma de explicar a escolha dos consumidores por esses alimentos (Daugbjerg et al., 2014; Demirtas, 2019; Freyer et al., 2014; Thorsøe et al., 2016; Truninger, 2013). Enquanto alguns autores argumentam que esses dois fatores estão diretamente relacionados, ou seja, quanto mais informação, mais confiança (Demirtas, 2019; Freyer et al., 2014), outros pesquisadores indicam que estar mais informado não necessariamente favorece a escolha por produtos orgânicos e, muitas vezes, pode até mesmo prejudicar a confiança. Para estes últimos, poderia ocorrer uma "desmistificação" da qualidade orgânica, que levaria a uma redução na percepção de seus benefícios (Thorsøe et al., 2016; Truninger, 2013).

Efetivamente, a confiança serve como uma forma de simplificação de complexas relações sociais, tornando dispensável compreender a totalidade do sistema agroalimentar para realizar escolhas de alimentos. Dessa maneira, a confiança atua entre dois extremos, tomados aqui como ideais-tipo (Weber, 2011): o conhecimento absoluto e a ignorância absoluta. No primeiro extremo, não há risco, logo a confiança é desnecessária. No segundo polo, as ações tornam-se imprevisíveis (Thorsøe et al., 2016).

Nesse quadro, a informação permite aos consumidores refletir e avaliar as diferenças entre os alimentos orgânicos e não orgânicos (Thorsøe et al., 2016). Por um lado, o excesso de informação pode aumentar a desconfiança por expor riscos antes desconhecidos (Truninger, 2013) ou gerar uma quebra de expectativas (Daugbjerg et al., 2014). Por outro lado, a falta de informação pode induzir nos consumidores falsas expectativas (Daugbjerg et al., 2014) ou até mesmo suscitar uma confiança não reflexiva, denominada "cega", que é muito mais suscetível a provocar erros e favorecer fraudes (Thorsøe et al., 2016). 
Dessa forma, a confiança se situa em um espectro cuja polaridade é representada pelas confianças críticas/reflexivas e cegas (Thorsøe et al., 2016). Ambas são influenciadas pela maior ou menor informação, cujo aumento pode gerar efeitos positivos no consumo de alimentos orgânicos (Daugbjerg et al., 2014; Demirtas, 2019; Thorsøe et al., 2016). De fato, muitos consumidores reflexivos procuram uma quantidade "ideal" de informação que seja suficiente para tomar decisões adequadas, mas sem ser excessiva, a ponto de confrontar parte de seus valores e comprometer suas rotinas (Thorsøe et al., 2016). Desse modo, diversos autores reconhecem a importância da informação para gerar confiança no sistema agroalimentar, mas outras variáveis, como valores e crenças sobre a qualidade alimentar, devem ser consideradas nesse âmbito (Meijboom et al., 2006; Truninger, 2013; Thorsøe et al., 2016).

Com essas referências, este artigo apresenta análises sobre RAA de alimentos orgânicos, em especial as feiras orgânicas enquanto espaços privilegiados de interações sociais, onde ocorrem forte sociabilidade, trocas de conhecimentos e até mesmo articulação política (Nierdele \& Marques, 2016). Nesse sentido, trata-se de problematizar as formas existentes de confiança, embasadas em relações interpessoais e em mecanismos institucionais, no mercado de alimentos orgânicos. Além dessa análise, o objetivo consiste em interpretar o papel da informação na tomada de decisão dos consumidores, considerando suas repercussões para o mercado orgânico. Para tal análise, o município de Sorocaba/SP é tomado como estudo de caso, apresentando uma ampla oferta de alimentos orgânicos em circuito mercantil com diversos atores e iniciativas. É importante esclarecer que este artigo não procura sugerir a forma de confiança superior ou o mecanismo de reconhecimento orgânico mais confiável, e tampouco negar pertinências de críticas a dispositivos formais dessa natureza.

\section{Metodologia}

O município de Sorocaba desempenha papel de grande importância regional por causa de sua vocação industrial e grande fluxo de migração pendular. De acordo com o Instituto Brasileiro de Geografia e Estatística (2018), o município possui uma população de 659.871 habitantes (2017) distribuídos em uma área total de 450,382 km² (2016), com uma densidade demográfica de 1.304,18 hab $/ \mathrm{km}^{2}$ (2010). Por suas características, Sorocaba constitui um grande mercado potencial para os alimentos orgânicos, tanto pela quantidade de iniciativas agroecológicas como pela presença local de comunidade quilombola, dois assentamentos com projetos agroecológicos no município vizinho de Iperó, além da forte implantação da agricultura orgânica em municípios próximos, como Piedade e Ibiúna. Esses agricultores são apoiados pelo Núcleo de Agroecologia Apêtê Caapuã (NAAC) - UFSCar Sorocaba, um grupo de extensão universitária que auxiliou também na etapa quantitativa desta pesquisa. Vale ressaltar que a atividade agrícola no município em si é pequena, mas intensa em seu entorno.

Como etapa prévia da pesquisa, foram utilizados dados coletados no âmbito de um projeto de extensão, obtidos por meio de um questionário sobre o consumo de alimentos orgânicos, aplicado por meio de um levantamento on-line. Este último se fundou em abordagem exploratória, com corte transversal, amostragem não probabilística por conveniência, tendo sido realizado por questionário autoaplicável pela internet (Freitas et al.. 2000).

O questionário consistiu em 30 perguntas, cujas possibilidades de respostas variavam entre: descritivas, binomiais, únicas e múltiplas escolhas. Para sua elaboração, as referências de Agovino et al. (2017), Hansen et al. (2018) e Pereira et al. (2015) foram muito úteis.

O levantamento enfocou os consumidores de alimentos orgânicos na região de Sorocaba, incluindo quatro municípios do entorno. Para divulgação do questionário, foram utilizadas mídias 
sociais do NAAC, dos membros envolvidos e dos próprios pesquisadores a fim de abranger o máximo de participantes. O questionário permaneceu disponível em site web durante todo o mês de fevereiro de 2018. Ao total, foram contabilizados 452 participantes válidos, sendo 363 residentes em Sorocaba. Os dados referentes a essa etapa exploratória da pesquisa estão indicados neste artigo como Pessoas que Responderam ao Levantamento On-line (PRLO).

No momento da pesquisa, em 2018/2019, a cidade de Sorocaba contava com cinco feiras orgânicas: Feira Orgânica do Parque Campolim, Feira Orgânica do Parque Chico Mendes, Feira Orgânica do Sorocaba Shopping, Feira Orgânica do Mercado Distrital e Feira de Transição Agroecológica e da Agricultura Familiar da UFSCar Sorocaba. Além das feiras, existiam lojas especializadas em alimentos orgânicos/naturais, entregas de cestas e uma iniciativa de "Comunidade que sustenta a Agricultura" (CSA). Esta última consistia em um grupo de consumidores e produtores formado a partir de compromissos mútuos, com base na noção de coprodução' (Torunsky, 2019).

Na principal etapa da pesquisa, foram realizadas entrevistas semiestruturadas com Pessoas que Consomem Alimentos Orgânicos (PCAO), consideradas aqui como aquelas que procuram integrar produtos orgânicos em suas dietas. Para a efetivação das entrevistas, foram selecionados diferentes pontos de venda de alimentos orgânicos, a fim de caracterizar diferentes hábitos e motivações desses consumidores. Nessa metodologia, foi formulada uma pergunta central ampla - Qual é sua motivação para consumir alimentos orgânicos? - para guiar a entrevista, com questões auxiliares para estimular o entrevistado, quando necessário, a saber: "Quais alimentos orgânicos você consome e com que frequência?"; "Há quanto tempo consome orgânicos?"; “Em que locais você adquire os produtos e por quê?"; "Quais são os critérios de escolha para os produtos orgânicos?"; "Quais são as dificuldades que você encontra para consumir orgânicos?". A amostragem foi definida por saturação teórica (Fontanella et al., 2011), levando em consideração os diferentes locais de venda da cidade.

Nas entrevistas presenciais, foram consideradas as cinco feiras orgânicas mencionadas, uma loja especializada (Vendinha de Orgânicos) e a CSA (ponto de retirada). Também foram realizadas entrevistas por telefone para alcançar consumidores que recebiam os produtos diretamente em suas residências. Além desses interlocutores, foram entrevistados consumidores que adquiriam orgânicos em supermercados. No entanto, por causa das barreiras impostas por seus responsáveis, que não permitiram realizar essas entrevistas no interior de suas lojas, foi feita a opção por contato telefônico com consumidores identificados no levantamento online. Essa etapa da pesquisa ocorreu entre fevereiro e maio de 2019. Ao total, foram realizadas 90 entrevistas. Vale ressaltar que, no decorrer dessas duas etapas, com exceção de cinco pessoas contatadas por telefone, não houve sobreposição de participantes.

Para o processamento dos dados, foi necessário estabelecer determinados critérios: para o levantamento on-line, os questionários preenchidos indevidamente ou respondidos por residentes em regiões muito distantes foram excluídos da pesquisa. Por outro lado, foram incluídos moradores de quatro municípios, além de Sorocaba: Araçoiaba, Iperó, Salto de Pirapora e Votorantim. Em razão da proximidade, suas relações com o município de Sorocaba são intensas.

Quanto à análise das entrevistas, foi desenvolvido, previamente, um modelo para identificar referências e valores utilizados pelos consumidores em seus discursos. Após essa preparação

1 A CSA é uma organização de produtores e consumidores em que estes últimos apoiam direta e previamente agricultores locais que fornecerão seus alimentos. Esses produtores se engajam em fornecer uma quantidade adequada de alimentos de qualidade para atender às necessidades e expectativas dos consumidores. Neste acordo geral de economia solidária, podem ocorrer muitas variações, dependendo dos recursos e desejos dos participantes (Torunsky, 2019). A primeira CSA brasileira nasceu no bairro Demétria, em Botucatu/SP, berço de implantação da agricultura biodinâmica no Brasil (Moruzzi Marques \& Blanc, 2000). 
teórica, as entrevistas efetuadas foram tratadas, com a transcrição e o exame de seu teor, mobilizando a análise de conteúdo.

\section{O perfil do consumidor}

Em linhas gerais, as PRLO foram majoritariamente mulheres (81\%), com alto grau de escolaridade (75\% ingressaram no ensino superior), principalmente na faixa de 18 a 35 anos (48\%), com renda média elevada (47\% apresentaram rendimentos acima de $\mathrm{R} \$ 3.000,00$ ) e morando em núcleos familiares pequenos com duas ou três pessoas (58\%). Quanto aos locais de compra, as PRLO se utilizam predominante das feiras orgânicas (62\%), dos supermercados (47\%), de lojas especializadas (26\%) e de aquisição de cestas (9\%). Neste último caso, não houve distinção entre CSA e formas de entregas a domicílio. Em relação à frequência de consumo das PRLO, 49\% podem ser consideradas como consumidoras frequentes (mais de uma compra realizada de orgânicos na semana), e 49\%, como ocasionais (menos de uma vez na semana), sendo que $2 \%$ indicaram não consumir esses alimentos.

Em relação às entrevistas, as PCAO interpeladas foram, igualmente, na maioria mulheres (67\%), possuindo alto grau de escolaridade (87\% com ingresso no ensino superior). Entre as faixas etárias, a prevalente foi entre 25 e 35 anos (34\%). Quanto à renda, as PCAO apresentaram uma média elevada, visto que $61 \%$ das entrevistadas desse grupo declararam rendimentos acima de $\mathrm{R} \$ 3.000,00$ mensais, além de indicarem, em sua maioria, morar em núcleos familiares pequenos com duas a três pessoas (72\% das PCAO). Esses dados se coadunam com a literatura sobre o tema (Conselho Brasileiro da Produção Orgânica \& Sustentável, 2019; Rana \& Paul, 2017).

Em relação aos seus hábitos de compra, as feiras se situavam como principal forma de aquisição de produtos orgânicos (81\%), seguidas pelos supermercados (43\%), lojas especializadas (18\%) e CSA (17\%). Entre os itens adquiridos, foram destaques as verduras e os legumes, com as frutas sendo menos assinaladas. Já alimentos processados, grãos e derivados de animais foram ainda menos mencionados, o que se explica em parte por sua escassa produção na região. Em relação à frequência de consumo, 79\% das PCAO podiam ser consideradas como consumidoras frequentes, e $21 \%$, como ocasionais.

\section{Relações de confiança}

As duas modalidades de confiança abordadas anteriormente (interpessoais e mecanismos institucionais) são encontradas em diversas situações dentro do mercado de alimentos orgânicos. Quando há uma maior proximidade entre os produtores e consumidores, a confiança construída a partir de relações interpessoais torna-se proeminente (Cassol \& Schneider, 2017), enquanto, em cadeias mais longas, os mecanismos institucionais são cruciais.

Como já mencionado, a implantação de mecanismos institucionais de regulação de alimentos orgânicos se sustenta na Lei $n^{\circ} 10.831$, de 2003, que reconhece duas formas de garantia orgânica: (1) aquelas certificadas por organismo reconhecido oficialmente (incluindo SPG) ou (2) aquelas realizadas por agricultores familiares inseridos em processos próprios de OCS. Neste artigo, doravante, serão considerados alimentos orgânicos certificados (que recebem o selo orgânico) aqueles provenientes de produções do primeiro caso. Para o segundo caso, os produtos são identificados como "orgânicos reconhecidos via OCS".

Esta última, mesmo amparada em mecanismo institucional, tem nas relações interpessoais elemento fundamental de sua lógica. Desta maneira, sua existência se funda em relação de confiança entre os produtores participantes, podendo ser entendidas como um dispositivo 
formal que visa validar relações interpessoais de confiança. Dessa forma, a OCS propicia a agricultores que não conseguiriam arcar com a certificação um acesso à garantia orgânica. Por conta desse fator, é atualmente a forma mais utilizada em quantidade de agricultores (Leão, 2019).

Com efeito, a proximidade exigida pelas OCS entre consumidores e produtores cria uma situação propícia ao desenvolvimento de relações de confiança interpessoal. Muitas vezes, o aspecto formal da OCS passa despercebido pelas PCAO. No entanto, vale ressaltar que relações interpessoais de confiança não são característica exclusiva das OCS, visto que qualquer transação entre consumidor e vendedor está perpassada por uma relação dessa natureza.

A proximidade desejada nas OCS é muito recorrente nas feiras, que se caracterizam por intensa sociabilidade, com muita troca de informações, favorecendo o estabelecimento de laços de confiança, o que é particularmente evidente naquelas de produtores orgânicos. Para Portilho \& Castañeda (2011), as feiras orgânicas são um primeiro contato que muitas pessoas realizam com os sistemas de reconhecimento orgânico. Em diversas entrevistas, é nítido que o diálogo com os feirantes, a troca de informações e até mesmo a consolidação de uma relação de amizade se mostraram como meio de reforço de confiança para a compra de alimentos nesse tipo de equipamento de abastecimento.

O sentimento de confiança forja certa solidariedade entre o feirante e o consumidor, muitas vezes assumindo o papel de substituto da certificação orgânica, como mencionado por Nierdele \& Marques, (2016). Para ilustrar essa situação, foram considerados os dados obtidos no levantamento on-line. Quanto ao reconhecimento dos produtos orgânicos, 40\% das PRLO se referiam à credibilidade do vendedor, enquanto $47 \%$ apontaram para o selo ou certificado orgânico. Em outra pergunta, os participantes mencionaram seus critérios para identificar um alimento orgânico. Entre as respostas, 90\% das PRLO mencionaram a ausência de uso de agrotóxicos, $67 \%$ consideraram o não uso de fertilizantes industriais e apenas $46 \%$ acreditavam que os produtos passavam por algum processo de certificação orgânica.

Com esses dados, é possível supor que mais de $50 \%$ dos consumidores conheciam pouco ou nada sobre a certificação orgânica. Para a maioria das PRLO, os alimentos orgânicos eram aqueles que não foram tratados com agrotóxico. Por mais que essa percepção esteja parcialmente correta, não reflete exatamente o que é um alimento orgânico, repercutindo em problemas para sua comercialização.

Esses dados contrastam com aqueles obtidos por Conselho Brasileiro da Produção Orgânica \& Sustentável (2019) em pesquisa com consumidores orgânicos em 11 capitais do país: 90\% dos entrevistados acreditavam ser obrigatória a utilização do selo para certificar um produto orgânico. Esse resultado leva a pensar que os consumidores de capitais possam estar mais sensibilizados sobre o papel das formas de reconhecimento orgânico, em razão, provavelmente, de uma maior dependência de cadeias longas de comercialização, que intrinsecamente se apoiam nesses mecanismos legais.

Em todo caso, a forma de confiança que guia a aquisição do alimento orgânico pelos consumidores é reveladora de escolhas. De fato, um grande número de entrevistados indicou as relações interpessoais como forma principal pela qual tinham confiança na qualidade do produto e, por essa razão, optavam por comprar orgânicos em feiras (62\% entre as PRLO e $81 \%$ nas P(AO). No caso de oito PCAO entrevistadas, a preferência por feiras ocorreu por confiarem, conhecerem e até mesmo terem relação de amizade com os feirantes. Contudo, esse tipo de relação não é exclusivo das feiras: uma consumidora aposentada apresentou a mesma opinião em relação às entregas de cestas em sua casa; uma jovem terapeuta (29 anos) manifestou essa visão sobre uma loja especializada; outro consumidor aposentado e uma jovem 
professora (29 anos) declararam ter essa perspectiva em relação à CSA. No caso desta última, o sentimento de confiança transparece ainda mais do que em relação às feiras orgânicas: "quanto mais próxima a relação, mais confiança se cria". De acordo com Truninger (2013), o sentimento de pertencimento a um grupo nos consumidores contribui para reforçar laços de amizade, solidariedade e confiança.

De outra parte, a confiança (ou desconfiança) pode se dirigir para produtores/feirantes específicos. O caso de um funcionário público de 34 anos é ilustrativo. Esse interlocutor frequentava uma das feiras há anos e comprava de todos os feirantes, com uma única exceção, por desconfiar da procedência de seus produtos. Segundo esse consumidor, o feirante em questão comercializava produtos muito distintos dos demais, indicando que não eram produzidos na região. Para o entrevistado, tal prática transformava o feirante em atravessador, deixando de ser produtor. Esse caso revela que PCAO mais informadas e com mais estímulos reflexivos podem questionar uma "validade universal" das relações interpessoais como meio para boas escolhas alimentares. Assim, suas preferências se desenvolvem em função de confiança em determinados feirantes, escolhidos a partir de um filtro crítico.

Casos de preferências por indivíduos/estabelecimentos específicos são comuns, mas normalmente envolvem também outros fatores além da confiança, como preços e diversidade de produtos. Aqui, é oportuno discutir a questão da fidelidade dos consumidores. Para que esta última se desenvolva, é necessária uma interação de confiança entre as partes (Dias et al., 2016). Dessa forma, a fidelização a determinado produtor/feirante/estabelecimento reflete obrigatoriamente confiança do consumidor.

Essas relações mais próximas de lealdade podem ser observadas com clareza na CSA. Aliás, aqui, são poucas as PCAO (apenas 2 de 15) que mencionaram a palavra "confiança" em relação aos agricultores. De fato, o discurso predominante é de fortalecer/participar da comunidade, o que foi mencionado por seis interlocutores. $\mathrm{Na}$ CSA, a proximidade e a subsequente confiança com os produtores são peças fundamentais para a existência do grupo. Com efeito, as PCAO acabam construindo relações interpessoais sólidas, de tal maneira que os mecanismos institucionais de regulação nem sequer foram mencionados, mesmo existindo (no caso, os produtores são certificados via SPG). De fato, a CSA organiza visitas e eventos esporádicos, reunindo agricultores e consumidores, aprofundando ainda mais essa relação².

Efetivamente, em muitos casos, a valorização das relações interpessoais é preferida em detrimento de mecanismos de certificação orgânica, como mostra o depoimento de um jovem consumidor (31 anos), com formação em engenharia agronômica: "no país como o nosso que se duvida da credibilidade de tudo, no momento que você acessa o produtor, eu acho que você tem certeza da garantia do produto". Nessa passagem de seu discurso, está clara uma confiança profunda nessas relações com o produtor e até mesmo uma descrença dos mecanismos institucionais. Essa confiança nem sempre é benéfica ao consumidor. A suspensão de um pensamento crítico acaba sujeitando às PCAO a dissimulações, como veremos adiante.

Por ora, vale ressaltar que esse fenômeno ocorre porque, como indicam Thorsøe et al. (2016), a confiança nos mecanismos institucionais é substituída por aquela interpessoal por conta de seu apelo emocional. De fato, argumentos de base emocional são muito efetivos na decisão de consumir ou não alimentos orgânicos (Vega-Zamora et al., 2019).

A propósito, casos de desconfiança em relação aos dispositivos institucionais não ocorreram apenas nas entrevistas, mas também no levantamento on-line. De fato, 10,4\% das PRLO alegaram ter falta de confiança na procedência/certificação. Obviamente, essa desconfiança

\footnotetext{
${ }^{2}$ Apesar da existência de outros modelos de organizações fundadas na construção de laços de confiança entre consumidores e produtores, apenas a CSA foi encontrada na região.
} 
pode afetar tanto os mecanismos institucionais quanto as relações interpessoais. Em nossas interlocuções de pesquisa, muitos feirantes mostraram preocupação com casos de fraudes envolvendo orgânicos e com sua repercussão negativa na confiança depositada pelas PCAO nas feiras. Para Holland (2016), todos os bens de crença (orgânicos inclusos) estão inseridos em um sistema que incentiva fraudes, visto que os preços elevados dos produtos estimulam um comportamento oportunista daqueles que querem lucrar sem maiores comprometimentos, sem temer a perda de reputação no longo prazo.

Segundo uma das feirantes, a desconfiança nas feiras leva os consumidores a preferir os supermercados por estes passarem uma imagem mais confiável, graças a muita publicidade. Quanto a esse ponto, é válido levantar questões sobre o grau de confiabilidade nos supermercados entre as PCAO.

Efetivamente, um grupo de sete PCAO interpeladas na pesquisa se mostrou explicitamente avesso a comprar orgânicos em supermercados. Seus argumentos são apresentados a seguir:

Acredito mais na feira do que no [super]mercado (Consumidor de 74 anos, aposentado).

No [super]mercado a gente nunca tem certeza que é realmente orgânico, aqui [na feira] a gente sabe o que é (Consumidora de 59 anos, aposentada).

Aqui [na feira] eles são certificados. Acho que aqui não tem mentira [...], lá [no supermercado] alguns até têm certificado, mas não sei se dá para confiar no que o supermercado vende (Consumidora de 41 anos, contadora).

[o supermercado] está sempre ali [...] o preço é diferente, mas aí entra outra visão [...] [o orgânico] é uma mudança de dentro para fora (Consumidora de 30 anos, professora de educação física).

O modelo de supermercados passou a dominar o sistema de distribuição alimentar desde os anos 1970 no Brasil. Dessa forma, não é de se estranhar que essa hegemonia também se alastre pelo mercado de alimentos orgânicos. Cada vez mais, é maior o número de supermercados com seções de orgânicos. Contudo, como consta no caso de sete dos interlocutores, há uma parcela das PCAO que desconfia das redes de supermercados, explicitando, muitas vezes, suas desvantagens em relação às feiras. No caso de uma entrevistada, essa desconfiança extrapola para os mecanismos de certificação. Nessa mesma linha, a pergunta sobre os sentimentos ao comprar alimentos orgânicos no supermercado levou um consumidor da CSA a reagir da seguinte forma: "de cara sinto aquela desconfiança, assim, nossa, será que é mesmo [orgânico]? Porque está no supermercado, mas você não sabe o pessoal que está envolvido" (Consumidor de 25 anos, professor). Discursos semelhantes podem ser encontrados em outras entrevistas, oscilando entre simples desconfiança dos supermercados, confiança maior em produtores do que nestes últimos e maior crédito nas feiras orgânicas certificadas. Em todas essas perspectivas, é possível observar duas oposições principais: entre RAA e sistema agroalimentar industrial e/ou entre mecanismos institucionais de reconhecimento orgânicos e relações de confiança interpessoais.

Para as PCAO simpatizantes das RAA, as redes varejistas de supermercados fazem parte do sistema agroalimentar industrial produtivista. Por essa razão, não merecem sua confiança, o que os incitam a procurar alternativas. Muitas vezes, essa desconfiança é transferida para os mecanismos institucionais de reconhecimento orgânico, como constatado nos discursos expostos. 
De fato, é frequente uma associação entre a certificação orgânica e as regulações impostas pelos agentes hegemônicos do sistema agroalimentar. Contudo, a certificação não é uma exclusividade do modelo agroalimentar industrial, visto que muitos produtos nas RAA também são certificados. Essa associação cria situações que parecem paradoxais, como no caso de uma consumidora de 68 anos, aposentada, que não confiava na certificação dos produtos do supermercado, mas, na feira, depositava confiança na banca que expunha o certificado de orgânicos obtido na mesma empresa que também certificava produtos de supermercados. Nesses casos, há uma desconfiança no sistema agroalimentar industrial, muito mais do que uma descrença nos mecanismos de certificação.

Dessa forma, é possível relativizar bastante a visão da feirante, segundo a qual os consumidores confiam mais nos supermercados. Em casos encontrados na pesquisa, as PCAO preferiam adquirir orgânicos no supermercado não por uma questão de confiança, mas sim por outros fatores, como praticidade e oferta mais abundante. Por outro lado, o risco de fraudes no reconhecimento orgânico causa prejuízos à imagem do produto orgânico de modo geral.

Com efeito, oito entrevistados expuseram não confiar convictamente nos mecanismos de certificação. Por exemplo, uma consumidora de 28 anos, engenheira de produção, consumia poucos alimentos orgânicos, pois sua família acreditava que "orgânico no Brasil é uma farsa. [Assim] vou pagar caro para uma coisa que é mentira". Outro depoimento nesse sentido foi obtido com uma consumidora de 59 anos, modelista, que tinha dúvidas se todos os produtos que comprava nas feiras eram de fato orgânicos. De todo modo, essa interlocutora os adquiria mesmo assim, pois, segundo suas palavras, "tem que ter boa-fé". Nesse quadro, é incontestável que fraudes potencializam os prejuízos para a imagem da produção orgânica, sobretudo entre aqueles consumidores que são mais hesitantes.

Um último exemplo de como se manifesta a relação entre informação e confiança pode ser tomado com elementos obtidos em entrevistas com frequentadores das feiras de transição agroecológica. Como indicado na legislação municipal (Sorocaba, 2018), as feiras orgânicas visam ao desenvolvimento da agricultura orgânica no município e, por essa razão, permitem que agricultores em processo de transição possam participar, mesmo sem o reconhecimento orgânico oficial definitivo. De fato, essa permissão estimula os agricultores a se tornarem orgânicos, participando antecipadamente das feiras. Todavia, essa situação nem sempre é bem-vista pelas PCAO:

As bancas que não têm certificação e acabam vendendo como produto orgânico, aí você fica naquela dúvida, será que é, será que não é? Esse também é um dos problemas. Por isso acabamos comprando só daquelas pessoas que conhecemos, que temos certeza que é [orgânico], por isso acabamos comprando uma variedade reduzida, porque aquelas pessoas só têm aqueles produtos (Consumidora de 52 anos, funcionária pública).

O marido dessa entrevistada manifesta a propósito o seguinte incômodo:

\footnotetext{
Inclusive eles praticam o preço de orgânico, mas não têm certificação. Isso é um problema, porque são eles que têm a maior variedade, você fica preso nos mesmos produtos, porque não confia no outro [...] gera uma dúvida e você acaba não comprando (Entrevistado de 61 anos, aposentado).
}

Para esse casal, a abertura da feira para produtores sem reconhecimento orgânico, de fato, é vista como um revés para aqueles com acreditação oficial. Ademais, cria uma dúvida quanto à qualidade orgânica dos alimentos, desestimulando a compra. Por mais raros que sejam esses casos, tal visão mostra como PCAO informadas podem ser críticas e criteriosas. O oposto pode ser identificado naqueles mais desinformados, que podem confiar na qualidade de produtos mesmo sem possuir referências minimamente fidedignas. 


\section{Consumidores desinformados ${ }^{3}$ e mercados informais}

Para um olhar analítico sobre a desinformação das PCAO, o trabalho de Freyer et al. (2014), tipificando os consumidores a partir de seus níveis de informação e confiança sobre selos e rótulos, é muito útil. Para esses autores, há três tipos principais de consumidores: o primeiro confia nas formas de controle e certificação sem se informar sobre esses dispositivos; o segundo confia nesses dispositivos, mas procura por informações adicionais para além do selo; enfim, o terceiro, além de informado, é engajado em formas fundadas em confiança a partir da relação direta entre o produtor e o consumidor.

Em sua interpretação, os autores estimam que a confiança possa se estabelecer sem nenhum conhecimento, recorrendo aos mecanismos institucionais de garantia de determinada qualidade. À medida que desenvolve uma melhor compreensão dos processos produtivos, o consumidor pode se tornar cada vez mais participativo e engajado, desenvolvendo mais relações interpessoais nesse âmbito (Freyer et al., 2014). Contudo, podemos apontar para uma insuficiência nesse modelo: maior confiança interpessoal pode não se associar a um maior nível de informação. Nos casos de confiança cega, ocorre uma grande simplificação da realidade a partir de relações pessoais que substituem o conhecimento e a informação. Dessa forma, podem prevalecer opiniões sem base factual oriundas de comunicação entre pessoas com afinidades. Assim, convém analisar se a confiança é de tipo reflexivo ou de tipo cego (Thorsøe et al., 2016).

Para discutir mais profundamente essa questão, os casos de dois consumidores (o primeiro engenheiro agrônomo de 31 anos e o segundo aposentado de 67 anos) são emblemáticos. Ambos questionam os mecanismos institucionais de garantia orgânica, em particular por não confiar na fiscalização no Brasil. Dessa maneira, depositam sua "confiança nos produtores". Assim, o segundo interlocutor compra alimentos "orgânicos" em uma horta urbana próxima de sua residência. O problema é que essa produção não é orgânica, como foi possível constatar na pesquisa por procedimentos de tipificação da horta urbana em questão. Equívocos dessa natureza significam que o consumidor acredita consumir orgânicos por confiar em seu comerciante, mas não tem informação suficiente para até mesmo identificar se os alimentos são orgânicos.

Portanto, Freyer et al. (2014) não foram capazes de incluir essas situações em seu modelo. Um consumidor que confia em relações diretas com o comerciante, mas é mal-informado, comprando alimentos por acreditar serem orgânicos, com pouca reflexão sobre sua ação, pode se enganar profundamente.

Esses casos podem ser mais comuns do que se imagina. Segundo Barbosa et al. (2011), a partir de dados de sua pesquisa, $93 \%$ dos entrevistados consideravam saber o que era alimento orgânico. Porém, esses números não significavam um elevado conhecimento, pois não foi avaliado seu nível de profundidade. Uma dimensão similar foi encontrada por Pereira et al. (2015): 90\% dos entrevistados manifestavam saber a diferença entre alimentos orgânicos e convencionais, porém novamente o grau de precisão desse conhecimento não foi avaliado. A falta de conhecimento das PCAO sobre os processos envolvendo esses alimentos foi identificada em nível internacional (Thorsøe et al., 2016). De fato, esse frágil nível de informação entre as PCAO se explica também pelas complexas diferenciações existentes no mercado orgânico (alimento biodinâmico, agroecológico, sem agrotóxicos, oriundo da agricultura familiar, natural etc.). Não é surpreendente que, em meio a tantas caracterizações de produtos alimentares nesse campo, os consumidores possam se confundir.

\footnotetext{
3 Vale ressaltar aqui que "desinformação" pode se relacionar tanto à falta de informação quanto ao acesso de informações erradas e imprecisas.
} 
Efeitos dessa ausência de clareza podem ser ilustrados com depoimentos de nossos entrevistados. Muitos de nossos interlocutores indicaram adquirir orgânicos de fornecedores "informais", sem reconhecimento orgânico, tais como vendedores de rua, hortas urbanas ou bancas em feiras convencionais. Assim, esses consumidores escolhem consumir produtos orgânicos (com uma visão pouco fundamentada) em situações informais, sem nenhum dispositivo de reconhecimento dessa qualidade. Dessa forma, em alguns casos, houve até mesmo confusão entre alimentos orgânicos e hidropônicos.

Nessas circunstâncias, é possível afirmar que as diferentes formas de confiança provocam uma clivagem entre formal e informal no mercado de alimentos orgânicos. O primeiro contempla os produtos que são submetidos a um mecanismo de reconhecimento orgânico, seja por via de certificação ou OCS. De outra parte, o mercado informal existe exclusivamente a partir de uma relação de confiança interpessoal entre o vendedor e o consumidor, sem nenhum mecanismo regulador formal de autenticação da qualidade orgânica.

Vale ressaltar que esse mercado informal se desenvolve não apenas pela valorização das relações de confiança interpessoais, mas também pela negação dos mecanismos institucionais. Com efeito, no mercado formal, é comum que relações interpessoais reforcem a confiança nos produtos, com as feiras orgânicas constituindo o principal exemplo desse fenômeno. Também é importante salientar que mercados formais e informais não estão necessariamente vinculados a determinado local, pois, como veremos mais adiante, ambos podem coexistir em um mesmo lugar. Com essas características em mente, o Quadro 1 apresenta situações de mercados formais e informais.

Quadro 1: Mercados formais e informais de orgânicos

\begin{tabular}{|c|c|c|}
\hline Mercado & \multicolumn{2}{|c|}{ Formal } \\
$\begin{array}{c}\text { Formas de } \\
\text { confiança }\end{array}$ & $\begin{array}{c}\text { Utilização de mecanismos de garantia } \\
\text { da qualidade orgânica. }\end{array}$ & $\begin{array}{c}\text { Dependência das relações de confiança } \\
\text { interpessoais. }\end{array}$ \\
\hline Exemplos & $\begin{array}{c}\text { Produtores/feirantes com certificação; } \\
\text { produtores membros de OCS. }\end{array}$ & $\begin{array}{c}\text { Vendedores ambulantes; produtores } \\
\text { sem reconhecimento orgânico; feirantes } \\
\text { sem selo ou permissão. }\end{array}$ \\
\hline
\end{tabular}

Essa dicotomia entre o mercado formal e informal de orgânicos normalmente passa despercebida para muitas PCAO. A maioria das pesquisas envolvendo os consumidores de orgânicos focaliza seus hábitos em determinados locais (supermercados e/ou feiras), usualmente ligados ao mercado formal. No entanto, na maioria dos casos, o mercado informal funciona às margens ou longe desses equipamentos. Nas entrevistas, foi possível detectar sua ocorrência, sobretudo, nas figuras de vendedores ambulantes (particularmente em locais mais periféricos e distantes dos pontos de vendas de orgânicos), horticultores urbanos, vizinhos/familiares (com hortas domésticas e quintais produtivos) e feirantes em feiras convencionais. Essas transações ocorrem frequentemente de forma paralela ao mercado formal, visto que todas as entrevistas foram realizadas em espaços de sua existência.

Como já mencionamos anteriormente, a confiança também é afetada por diversos fatores tácitos e sensoriais. As PCAO constroem sua confiança nesses alimentos a partir de vivências pessoais de rotina diária (Thorsøe et al., 2016; Truninger, 2013). Ademais, vale lembrar que cada tipo de alimento está associado a valores simbólicos diferentes, logo suas avaliações em termos de confiança são distintas (Kjærnes et al., 2007).

Considerando os dados desta pesquisa, é evidente que há uma importante descrença e/ ou um desconhecimento do reconhecimento orgânico formal. Apenas uma parcela das PCAO reconhece sua importância. Dessa forma, é grande o espaço para crescimento de um mercado 
informal com base em relações de confiança e com depreciação de mecanismos oficiais de reconhecimento orgânico.

As dinâmicas desse mercado informal constituem questões bastante controversas. Por um lado, os alimentos ali comercializados podem até mesmo seguir as premissas de produção orgânicas, mas, por outro lado, podem ser apenas uma dissimulação para acessar um nicho de mercado em crescimento acelerado, atraindo consumidores dispostos a pagar mais por um alimento diferenciado.

Nesse âmbito, existem diversas situações que podem ser consideradas: agricultor orgânico que não possui recursos para arcar com a certificação; produtores que não têm clareza do que é a produção orgânica; fornecedores de alimentos que, deliberadamente, negam os mecanismos institucionais de reconhecimento da qualidade orgânica; e até mesmo comerciantes abusando da confiança dos consumidores.

Em todo caso, mesmo que os alimentos sejam produzidos com métodos considerados como orgânicos, a falta de um mecanismo institucional de reconhecimento acaba colocando esses produtores em situação similar (aos olhos da lei) àqueles que estão dissimulando suas verdadeiras práticas para ganho de forma desonesta. Em outras palavras, para o consumidor sanar suas dúvidas, os mecanismos institucionais de reconhecimento de orgânicos constituem o meio mais seguro. Porém, por causa da falta de informação sobre esses dispositivos, as incertezas (ou as falsas certezas) acabam permanecendo.

Um exemplo dessas incertezas pôde ser observado na feira do CEASA de Sorocaba, indicada por quatro entrevistados como um local para adquirir alimentos orgânicos, pois, segundo esses interlocutores, existiria uma banca orgânica entre as demais. Graças a uma visita ao local, os feirantes foram questionados quanto à qualidade orgânica dos alimentos, porém não eram produtores, e sim funcionários de uma associação, que se caracterizaram como agricultores de alimentos de época e cujos produtos não apresentavam certificação; enfim, esses assalariados foram incapazes de explicar os métodos produtivos. Trata-se de caso típico do mercado informal.

A propósito, vale ressaltar que, pela legislação, o ônus da prova quanto à qualidade orgânica recai sobre os agricultores. Dessa forma, cabe a esses últimos provar a procedência de seus produtos, seja pelos mecanismos de garantia institucionais, seja pelas relações interpessoais de confiança no caso das OCS.

As informações coletadas na pesquisa evidenciam que, para a maioria das PCAO que associam o alimento orgânico apenas a um cultivo isento de uso de agrotóxico, ignorando outros aspectos envolvendo a produção orgânica, a separação entre mercado formal e mercado informal praticamente não existe. Dessa forma, é um maior nível de informação sobre orgânicos que permite às PCAO perceber essa dicotomia.

De um lado, as PCAO pouco informadas que confiam nas relações interpessoais de maneira acrítica são mais propensas a alimentar o mercado informal, já que não consideram os mecanismos institucionais de reconhecimento de qualidade orgânica como forma de confiança complementar. Por outro lado, as PCAO com mais conhecimento e reflexividade são capazes de realizar escolhas mais conscientes e optar ou não por acessar o mercado informal, dependendo do quanto confiam nos produtores/feirantes.

Ainda mais complexo é o caso das feiras de transição agroecológica, pois fornecem uma situação peculiar: a permissão de participação para produtores sem reconhecimento orgânico formalizado cria um espaço de comercialização orgânica onde há suporte público para o convívio entre agricultores reconhecidos oficialmente como orgânicos e outros sem reconhecimento formal. Normalmente, essa problemática passa despercebida aos olhos do consumidor, mas, 
como visto nos depoimentos do casal de interlocutores mencionados anteriormente, tal incongruência pode ser mal apreciada pelas PCAO com olhar mais crítico e com forte confiança nos mecanismos institucionais. Esses casos, por mais que sejam incomuns, expõem uma problemática pouco visível sobre as feiras de transição agroecológica. Se os avanços no campo legislativo forem benéficos para a produção orgânica e agroecológica, a falta de critérios objetivos para enquadrar o processo e a duração da transição agroecológica podem abrir precedentes para abusos, insuflando um mercado informal de alimentos orgânicos. Contudo, não é possível avaliar se, no longo prazo, essas feiras serão benéficas ou prejudiciais à comercialização de orgânicos, o que é questão pertinente para averiguações futuras.

\section{Conclusão}

As relações de confiança interpessoais se mostram presentes em diversas situações de comercialização alimentar, cumprindo um papel importante de sociabilidade e mesmo de manutenção da cultura local, principalmente nas feiras orgânicas e em grupos de CSA. Contudo, quando essas relações levam a negligenciar os mecanismos institucionais de reconhecimento orgânico, condições favoráveis para o florescimento de um mercado informal de produtos orgânicos são abertas, com grandes margens para fraudes ou abusos.

O mercado informal não tem vocação para desfazer dúvidas, com esclarecimento sobre o que são alimentos orgânicos. Nessa medida, é propício para a oferta de produtos cuja qualidade orgânica não é minimamente assegurada. Trata-se de um quadro prejudicial à confiança nos orgânicos como um todo, da mesma maneira que fraudes prejudicam a imagem dos mecanismos institucionais de garantia de qualidade.

Os esforços para a conscientização sobre as características dos alimentos orgânicos, assim como suas diferenciações, tais como produtos agroecológicos e sem agrotóxicos, parecem insuficientes. Efetivamente, muitos consumidores não possuem essa clareza e acabam realizando escolhas equivocadas por confiar exclusivamente em relações interpessoais.

A propósito, estas últimas são normalmente consideradas como formas de promover laços de confiança em oposição aos mecanismos institucionais de reconhecimento orgânico, o que deveria ser bastante relativizado. A legislação brasileira permite, por meio das OCS, que as relações interpessoais desempenhem um importante papel para a validade formal de um produto orgânico. Dessa forma, a importância desse reconhecimento oficial, seja por certificação, seja por OCS, não deveria ser negligenciada.

Este artigo evidenciou as formas de confiança na qualidade de produtos orgânicos a partir das quais o consumidor decide adquiri-los. Realça-se a informação insuficiente com a qual esses consumidores realizam compras de alimentos orgânicos, fundadas frequentemente em "confiança cega". Com efeito, o desenvolvimento do mercado de alimentos orgânicos pode ser mais afetado não por preços elevados ou por pouca oferta/diversificação, como indicado pelos entrevistados, mas sim por falta de informação adequadamente disponível sobre esses produtos.

\section{Referências}

Agovino, M., Crociata, A., Quaglione, D., Sacco, P., \& Sarra, A. (2017). Good taste tastes good. cultural capital as a determinant of organic food purchase by italian consumers: evidence and policy implications. Ecological Economics, 141, 66-75. 
Anjos, F. S., \& Caldas, N. V. (2017). A dinâmica dos canais curtos de comercialização: o caso do Projeto Campagna Amica na Itália. Revista Sociedade e Estado, 32(3), 771-792.

Barbosa, S. C., Matteucci, M. B. A., Leandro, W. M., Leite, A. F., Cavalcante, E. L. S., \& Almeida, G. Q. E. (2011). Perfil do consumidor e oscilações de preços de produtos agroecológicos. Pesquisa Agropecuária Tropical, 41(4), 602-609.

Beck, U. (2011). Sociedade de riscos: rumo a uma outra modernidade (2. ed.). São Paulo: Editora 34.

Brasil. (2003). Lei no 10.831, 23 de dezembro 2003. Dispõe sobre a agricultura orgânica e dá outras providências. Diário Oficial [da] República Federativa do Brasil, Brasília.

Cassol, A., \& Schneider, S. (2017). Construindo a confiança nas cadeias curtas: interações sociais, valores e qualidade na Feira do Pequeno Produtor de Passo Fundo/RS. In M. Gazolla \& S. Schneider (Eds.), Cadeias curtas e redes alimentares alternativas. (pp. 195-218). Porto Alegre: Editora da UFRGS.

Conselho Brasileiro da Produção Orgânica \& Sustentável - ORGANIS. (2019). Panorama do consumo de orgânicos no Brasil 2019. Recuperado em 1 de novembro de 2019, de http:// organis.org.br/

Daugbjerg, C., Smed, S., Andersen, L. M., \& Schvartzman, Y. (2014). Improving ecolabelling as an environmental policy instrument: knowledge, trust and organic consumption. Journal of Environmental Policy and Planning, 16(4), 559-575.

Demirtas, B. (2019). Assessment of the impacts of the consumers' awareness of organic food on consumption behavior. Food Science and Technology, 39(4), 881-888.

Dias, V. V., Schuster, M. S., Talamini, E., \& Révillion, J. P. (2016). Scale of consumer loyalty for organic food. British Food Journal, 118(3), 697-713.

Fontanella, B. J. B., Luchesi, B. M., Saidel, M. G. B., Ricas, J., Turato, E. R., \& Melo, D. G. (2011). Amostragem em pesquisas qualitativas: proposta de procedimentos para constatar saturação teórica. Cadernos de Saúde Pública, 27(2), 389-394.

Freitas, H., Oliveira, M., Saccol, A. Z., \& Moscarola, J. (2000). O método de pesquisa survey. Revista de Administração, 35(3), 105-112.

Freyer, B., Bingen, J., \& Paxton, R. (2014). Can multicriteria assessment tools help build trust into organic products? Ecology and Society, 19(4), art5.

Hansen, T., Sørensen, M. I., \& Eriksen, M. R. (2018). How the interplay between consumer motivations and values influences organic food identity and behavior. Food Policy, 74, 39-52.

Holland, S. (2016). Lending credence: motivation, trust, and organic certification. Agricultural and Food Economics, 4(14), 1.

Instituto Brasileiro de Geografia e Estatística - IBGE. (2018). Município de Sorocaba. Recuperado em 8 de abril de 2018, de https://www.ibge.gov.br/estatisticas-novoportal/por-cidadeestado-estatisticas.html?t=destaques \&c=3552205

Kjærnes, U., Harvey, M., \& Warde, A. (2007). Trust in food: a comparative and institutional analysis. Basingstoke: Palgrave Macmillan.

Leão, V. O. P. S. (2019). Organizações de Controle Social na Região Metropolitana de São Paulo: relações de proximidade e de confiança em foco (Dissertação de mestrado). Escola Superior de Agricultura "Luiz de Queiroz", Universidade de São Paulo, Piracicaba.

McKnight, D H., \& Chervany, N. L. (1996) The meanings of trust (Technical report). University of Minnesota. 
McMichael, P. (2016). Regimes alimentares e questões agrárias. São Paulo: Editora Unesp; Porto Alegre: Editora da UFRGS.

Meijboom, F., Visak, T., \& Brom, F. (2006). From trust to trustworthiness: why information is not enough in the food sector. Journal of Agricultural \& Environmental Ethics, 19(5), 427-442.

Moruzzi Marques, P. E., \& Blanc, J. (2020). Contornos sinuosos de justiça ecológica. Raízes: Revista de Ciências Sociais e Econômicas, 40(2), 366-389.

Nierdele, P. A., \& Marques, F. C. (2016). Produção ecológica de alimentos e mudanças institucionais: implicações para a construção de novos mercados. In F. C. Marques, M. A. Conterato \& S. Schneider (Eds.), Construção de mercados e agricultura familiar (1. ed., pp. 275-310). Porto Alegre: Editora da UFRGS.

Paula, N. M. (2017). Evolução do sistema agroalimentar mundial: contradições e desafios. Curitiba: CRV.

Pereira, M. C., Müller, C. R., Rodrigues, F. S. A., Moutinho, A. B. A., Rodrigues, K. L., \& Botelho, F. T. (2015). Mudança no perfil sociodemográfico de consumidores de produtos orgânicos. Ciencia \& Saude Coletiva, 20(9), 2797-2804.

Portilho, F., \& Castañeda, M. (2011). Certificação e confiança face a face em feiras de produtos orgânicos. Revista de Economia Agrícola, 58(1), 11-21.

Rana, J., \& Paul, J. (2017). Consumer behavior and purchase intention for organic food: a review and research agenda. Journal of Retailing and Consumer Services, 38, 157-165.

Renting, H., Marsden, T., \& Banks, J. (2017). Compreendendo as redes alimentares alternativas: o papel de cadeias curtas de abastecimento de alimentos no desenvolvimento rural. In M. Gazolla \& S. Schneider (Eds.), Cadeias curtas e redes alimentares alternativas. (pp. 27-52). Porto Alegre: UFRGS.

Rossi, A., \& Brunori, G. (2017). As cadeias curtas de abastecimento na inovação dos Grupos de Aquisição Solidárias (GAS): a construção social das práticas (alimentares) sustentáveis. In M. Gazolla \& S. Schneider (Eds.), Cadeias curtas e redes alimentares alternativas. (pp. 83-104). Porto Alegre: Editora da UFRGS.

Schneider, S., \& Gazolla, M. (2017). Cadeias curtas e redes alimentares alternativas. In M. Gazolla \& S. Schneider (Eds.), Cadeias curtas e redes alimentares alternativas. (pp. 9-26). Porto Alegre: Editora da UFRGS.

Sorocaba (Município). (2018). Diagnóstico ambiental municipal. Recuperado em 22 de maio de 2020, de http://meioambiente.sorocaba.sp.gov.br/gestaoambiental/diagnostico-ambientalmunicipal/

Thorsøe, M. H. (2015). Maintaining trust and credibility in a continuously evolving organic food system. Journal of Agricultural \& Environmental Ethics, 28(4), 767-787.

Thorsøe, M. H., Christensen, T., \& Povlsen, K. K. (2016). Organics' are good, but we don't know exactly what the term means! Trust and knowledge in organic consumption. Food, Culture, \& Society, 19(4), 681-704.

Torunsky, F. (2019) Justificativas em torna das comunidades que sustentam a agricultura: um estudo de caso da CSA São Carlos/SP (Dissertação de mestrado). Escola Superior de Agricultura "Luiz de Queiroz", Universidade de São Paulo, Piracicaba.

Truninger, M. (2013). As bases plurais da confiança alimentar nos produtos orgânicos: da certificação ao "teste da minhoca". Ambiente \& Sociedade, 16(2), 81-102. 
Van der Ploeg, J. D. (2008). Camponeses e impérios alimentares: lutas por autonomia e sustentabilidade na era da globalização. Porto Alegre: Editora UFRGS.

Vega-Zamora, M., Torres-Ruiz, F.J., \& Parras-Rosa, M. (2019). Towards sustainable consumption: keys to communication for improving trust in organic foods. Journal of Cleaner Production, 216, 511-519.

Weber, M. (2011). A "objetividade" do conhecimento nas Ciências Sociais. In G. Cohn \& M. Weber (Eds.), Sociologia. São Paulo: Ática.

Recebido: Abril 18, 2021.

Aceito: Julho 27, 2021

JEL Classification: Q13, Q19 